\title{
Dilute proparacaine for the management of acute corneal injuries in the emergency department
}

\author{
Ian Michael Ball, MD; ${ }^{*}$ Jamie Seabrook, MA; ${ }^{\dagger}$ Nimesh Desai, BSc(Pharm), MD; ${ }^{\ddagger}$ Larry Allen, MD; ${ }^{\ddagger}$ \\ Scott Anderson, $\mathrm{MD}^{*}$
}

\section{ABSTRACT}

Objective: Dogma discourages the provision of topical anesthetics to patients with corneal injuries discharged from the emergency department because of the toxicity of concentrated solutions. We compared the analgesic efficacy of dilute topical proparacaine with placebo in emergency department patients with acute corneal injuries.

Methods: We conducted a prospective randomized controlled trial of adults with corneal injuries presenting to one of 2 tertiary care emergency departments in London, Ont. Patients were randomly assigned to groups receiving either $0.05 \%$ proparacaine or placebo drops as outpatients and were followed up to healing by a single ophthalmologist. Our primary outcome was pain reduction as measured on a $10-\mathrm{cm}$ visual analog scale.

Results: Fifteen participants from the proparacaine group and 18 participants from the placebo group completed the study. The mean age of the patients was 38.7 (standard deviation 12.3) years and the majority were male (85\%). Pain reduction was significantly better in the proparacaine group than in the placebo group, with a median improvement of 3.9 (interquartile range [IQR] 1.5-5.1) $\mathrm{cm}$ on the visual analog scale versus a median improvement of 0.6 (IQR $0.2-2.0) \mathrm{cm}(p=0.007)$. The proparacaine group was more satisfied (median level of satisfaction 8.0 [IOR 6.0-9.0] $\mathrm{cm}$ on a $10-\mathrm{cm}$ visual analog scale v. 2.6 [IOR 1.0-8.0] cm, $p=0.027$ ). There were no ocular complications or signs of delayed wound healing in either group.

Conclusion: Dilute topical proparacaine is an efficacious analgesic for acute corneal injuries. Although no adverse events were observed in our study population, larger studies are required to evaluate safety.

Keywords: proparacaine, pain, cornea, abrasion

\section{RÉSUMÉ}

Objectif : Le dogme déconseille aux médecins de remettre aux patients présentant des lésions cornéennes des anesthésiques topiques à leur sortie de l'urgence, en raison de la toxicité des solutions concentrées. Nous avons comparé l'efficacité analgésique de la proparacaïne diluée appliquée localement à celle d'un placebo chez des patients s'étant présentés à l'urgence avec des lésions cornéennes aiguës.

Méthodes : Nous avons réalisé un essai contrôlé randomisé prospectif auprès d'adultes ayant des lésions cornéennes et s'étant présentés à l'un des deux services d'urgence d'un centre hospitalier de soins tertiaires à London, en Ontario. Les patients ont été répartis au hasard entre des groupes recevant dans une clinique externe soit de la proparacaïne à 0,05\%, soit des gouttes d'un placebo. Ils ont été suivis jusqu'à la guérison par un seul ophtalmologiste. Notre principal critère d'évaluation était la réduction de la douleur, mesurée sur une échelle visuelle analogique (EVA) de 0 à $10 \mathrm{~cm}$.

Résultats : Quinze participants du groupe proparacaïne et 18 du groupe placebo ont terminé l'étude. L'âge moyen des patients était de 38,7 ans (écart-type de 12,3) et la majorité était de sexe masculin ( $85 \%$ ). La réduction de la douleur était significativement meilleure dans le groupe proparacaïne que dans le groupe placebo, avec une amélioration médiane de $3,9 \mathrm{~cm}$ (intervalle interquartile [IIO] de 1,5 à 5,1) sur I'EVA par rapport à une amélioration médiane de $0,6 \mathrm{~cm}$ (IIQ de 0,2 à $2,0, p=0,007)$. Le groupe proparacaïne était plus satisfait des résultats (niveau de satisfaction médian de $8,0 \mathrm{~cm}$ [IIQ de 6,0 à 9,0$]$ ) sur I'EVA contre $2,6 \mathrm{~cm}$ [IIQ de 1.0 à 8,0 ], $p=0,027$ ). Aucune complication oculaire ou aucun signe de retard de cicatrisation n'ont été notés dans les deux groupes.

Conclusion : La proparacaïne diluée appliquée localement est un analgésique efficace pour les lésions cornéennes aiguës. Bien qu'aucun effet indésirable n'ait été observé dans cette population d'étude, des études de plus grande envergure s'imposent pour évaluer l'innocuité.

\section{INTRODUCTION}

Acute corneal injuries are a common complaint in the emergency department. They cause significant patient

From the *Divisions of Emergency Medicine and Critical Care Medicine, Department of Medicine, the tDepartments of Pediatrics and Sociology and the ‡Department of Surgery, London Health Sciences Centre, London, Ont.

Submitted Oct. 20, 2009; Accepted Dec. 16, 2009

This article has been peer reviewed.

CJEM 2010;12(5):389-94 
morbidity, including pain, loss of sleep and missed work. The approach to pain management varies in this patient population and includes the following: no analgesia, oral or topical nonsteroidal anti-inflammatory drugs (NSAIDs), oral opiates and cycloplegics. ${ }^{1}$ Topical agents can reduce pain; however, their use must be limited. Topical NSAIDs have induced sterile corneal infiltrates. ${ }^{2}$ Textbooks state that prolonged topical application of local anesthetics is contraindicated ${ }^{3,4}$ because of their inhibition of mitosis and cellular migration. ${ }^{5}$ Local anesthetics are said to impair the ability of the corneal epithelium to oxidize glucose and pyruvate. ${ }^{5}$ Topical anesthetics can markedly decrease corneal sensation to touch, which is an important corneal protective mechanism. ${ }^{6}$ At commonly encountered concentrations (e.g., $0.5 \%$ proparacaine), these agents are also directly toxic to the cornea with prolonged and repeated use, ${ }^{5,7-9}$ causing increased corneal thickness, opacification, stromal infiltration and punctate epithelial defects. ${ }^{10-12}$

Several publications in the ophthalmology literature have reported that the outpatient use of more dilute topical anesthetics is safe and effective after photorefractive surgery. ${ }^{13-15}$ We asked whether dilute $0.05 \%$ proparacaine applied topically would be efficacious in patients with acute corneal injuries discharged from the emergency department. Our primary outcome was pain reduction from baseline as measured on a $10-\mathrm{cm}$ visual analog scale. Secondary end points included patient satisfaction with the study drug, use of medications for breakthrough pain, and signs of delayed wound healing or corneal toxicity on follow-up.

\section{METHODS}

\section{Design}

We performed a prospective randomized double-blind placebo-controlled trial on adults with corneal injuries.

\section{Setting and study population}

Our study was performed at 2 tertiary care emergency departments in London, Ont., with a combined census of approximately 120000 visits per year. We enrolled a convenience sample of adult patients during an 8-month period beginning in October 2005. Patients were excluded if they had any of the following: inability to consent to the study, allergy to any of the study medications, inability to attend follow-up appointments for any reason, or previous eye injury or pathology.

\section{Interventions}

Patients were randomly assigned to groups receiving either $0.05 \%$ proparacaine or a colour- and smellmatched placebo. The usual single-dose topical anesthetic used to facilitate eye examination in the participating emergency departments is $0.5 \%$ proparacaine. Our pharmacy diluted this usual medication 10-fold, emulating a previous postoperative study. ${ }^{15}$ Patients were instructed to use 2 to 4 drops of the study drug on an as-needed basis for the next 7 days. No minimum time interval between dosing was stipulated, allowing patients unlimited use of the study drug. A total volume of $40 \mathrm{~mL}$ was dispensed to each patient.

Participants were given a pain log, topical fluoroquinolone and tablets of $325 \mathrm{mg}$ acetaminophen with $30 \mathrm{mg}$ of codeine for breakthrough pain. Patients received an instruction sheet explaining how to use the pain logs as well as an information sheet explaining the goals of the trial. All patients included in the study were prescribed topical gatifloxacin, 1-2 drops every 2 hours to the affected eye while awake for the duration of the study period. They were instructed to take 1 to 2 tablets of the acetaminophen with codeine every 4 hours if needed. Patients were asked to record their use of oral analgesics, and to bring all unused pills to clinic follow-up appointments, where they were counted.

\section{Outcome measures}

Participants were asked to complete the visual analog scale $^{16}$ describing their pain immediately before, and 5 minutes after self-administration of the study drug. On the $10-\mathrm{cm}$ scale, 0 indicated "no pain" and 10 indicated "the worst imaginable pain." The pre- and postdrug visual analog scales were printed on the same sheet of paper, allowing the participant to see both scales at the time of scoring. The primary outcome was the mean difference in pain scores before and after drug administration as recorded by each study participant. Satisfaction was recorded by participants using a separate 10 -cm visual analog scale $(0=$ completely unsatisfied, $10=$ completely satisfied).

All patients attended for follow-up at an outpatient clinic on days 1, 3 and 5 after enrolment by a single ophthalmologist, who was unaware of the patient allocation. The ophthalmologist was directed to identify signs of delayed wound healing, increased corneal thickness, corneal opacification, new corneal epithelial defects or any other ocular pathology that could be related to 
either the initial injury or the use of study medication. Patients made additional visits thereafter at the discretion of the observing ophthalmologist. At the final ophthalmology clinic visit, the pain logs were collected.

\section{Patient recruitment}

The attending emergency physician and emergency medicine residents on duty recruited patients into the study. The total number of patients eligible for inclusion in the trial during the 8-month trial period was not recorded. No attempt was made to measure the severity of the corneal injury, either in the emergency department or at follow-up.

\section{Randomization and concealment}

Staff at the hospital pharmacy diluted the proparacaine and filled numbered vials with either proparacaine or placebo. These vials were distinguishable only by number. The randomization key was generated via a computer using the random number function of Excel (Microsoft). The lead author and pharmacist were the only 2 people with access to the randomization key. The randomization key was made available to the lead author only after study completion. The contents of the study drug vial were concealed from all personnel involved in patient care, as well as from the patients themselves. Treating physicians were instructed to select the next available vial to dispense to the participant at the time of enrolment. The allocation was confirmed by inspection of the numbered vial at follow-up.

\section{Ethics}

Patients provided written consent to the emergency physician at the time of enrolment as approved by our institution's research ethics board.

\section{Statistical analysis}

Data were analyzed using SPSS, version 15.0 (SPSS Inc.). Data are reported as means and standard deviations for normally distributed continuous variables, or medians and interquartile ranges (IQRs) for skewed continuous variables. Percentages were used for categorical variables. The Mann-Whitney test was used to compare differences in pain reduction, drug satisfaction and number of oral tablets taken between the groups.

\section{Sample size}

We determined that 16 participants in each group would be needed to have an $80 \%$ chance of detecting a pain reduction of $2 \mathrm{~cm}$ on the visual analog scale between the 2 groups, assuming an $\alpha$ of 0.05 , and a standard deviation of $2 \mathrm{~cm}$. We chose $2 \mathrm{~cm}$ to represent a clinically meaningful difference based on an informal survey of attending emergency physicians at our hospital.

\section{RESULTS}

Fifteen participants from the proparacaine group and 18 participants from the placebo group completed the study. Eight enrolled patients either did not use even a

\begin{tabular}{|c|c|c|c|c|c|}
\hline \multirow{3}{*}{$\begin{array}{l}\text { Variable } \\
\text { Patient age, yr }\end{array}$} & \multicolumn{4}{|c|}{ Group; median (IQR) } & \multirow{3}{*}{$\begin{array}{c}p \text { value }{ }^{*} \\
0.94\end{array}$} \\
\hline & \multicolumn{2}{|c|}{ Proparacaine } & \multicolumn{2}{|r|}{ Placebo } & \\
\hline & 38.0 & $(28.0-47.0)$ & 39.3 & $(27.0-46.0)$ & \\
\hline Pain reduction, $\dagger \mathrm{cm}$ & 3.9 & $(1.5-5.1)$ & 0.6 & $(0.2-2.0)$ & 0.007 \\
\hline Patient satisfaction, $\neq$ score & 8.0 & $(6.0-9.0)$ & 2.6 & $(1.0-8.0)$ & 0.027 \\
\hline Interval, § min & 192.5 & $(126.0-245.0)$ & 170.0 & $(120.0-246.0)$ & 0.80 \\
\hline Drops administered $\emptyset$ & 7.5 & $(3.0-9.0)$ & 5.0 & $(3.0-6.0)$ & 0.17 \\
\hline $\begin{array}{l}\text { Tablets of acetaminophen } \\
\text { with codeine taken** }\end{array}$ & 0.0 & $(0.0-2.0)$ & 2.0 & $(0.0-5.0)$ & 0.22 \\
\hline \multicolumn{6}{|c|}{$\begin{array}{l}\text { IQR = interquartile range. } \\
\text { *Wilcoxon rank sum test. } \\
\text { tPain reduction as recorded by patients on a } 10-\mathrm{cm} \text { visual analog scale. } \\
\text { †Patient satisfaction with the efficacy of study drug recorded by patients at the end of the study, where } 0=\text { not satisfied at all and } \\
10=\text { completely satisfied. } \\
\text { \$Median time interval between administration of the first and last drop of study drug for each time the study drug was used. } \\
\text { १The median number of drops of the study drug that patients self-administered each time the study drug was used. } \\
* \text { *The median number of tablets of acetaminophen }(300 \mathrm{mg}) \text { with codeine }(30 \mathrm{mg}) \text { used after administration of the study drug. }\end{array}$} \\
\hline
\end{tabular}


single dose of medication, did not record their pain in their pain logs or were lost to follow-up. These patients were removed from the trial entirely, and were not included in an intent to treat fashion.

The mean age in the proparacaine group was 38.0 years, and in the placebo group was 39.3 years. In the proparacaine group, $87 \%$ of participants were male, and in the placebo group $83 \%$ were male. All injuries were caused by trauma that had occurred within 24 hours of presentation to the emergency department.

Table 1 shows patient outcomes between the 2 groups. Pain reduction 5 minutes after administration of the study drug was significantly better in the proparacaine group than in the placebo group (Fig. 1) (median improvement 3.9 [IQR $1.5-5.1] \mathrm{cm}$ on the visual analog scale v. 0.6 [IQR $0.2-2.0] \mathrm{cm}, p=0.007)$. The proparacaine group was also much more satisfied (Fig. 2) (median level of satisfaction 8.0 [IQR 6.0-9.0] cm v. 2.6 [IQR 1.0-8.0] cm, $p=0.027$ ). The placebo group took more acetaminophen with codeine tablets (median 2.0 [IQR 0.0-5.0] tablets) than the proparacaine group (median 0.0 [IQR 0.0-2.0] tablets) but this difference was not statistically significant (Fig. 3) $(p=0.22)$.

There was no difference in frequency of administration of the study drug between the 2 groups based on pain logs. There were also no ocular complications or evidence of delayed wound healing in either group.

\section{DISCUSSION}

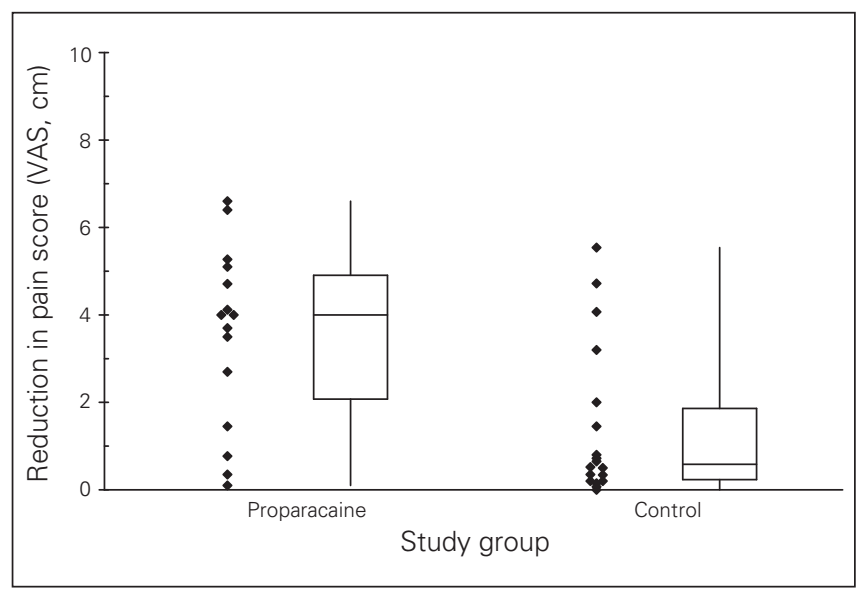

Fig. 1. Reduction in pain 5 minutes after drop application. The $\Delta$ between the mean pain score before administration of the study drug, and the mean pain score 5 minutes after administration is shown for each participant. The diamonds represent the mean $\Delta$ pain scores for each study participant. The upper and lower borders of each rectangle represent the 75 th and 25 th percentiles of mean pain reduction. The horizontal line within each rectangle represents the median pain reduction. $\mathrm{VAS}=$ visual analog scale.
Many physicians receive requests from patients for a topical anesthetic prescription after the initial dose administered in the emergency department provides complete relief. Dogma instructs us to never prescribe outpatient topical anesthesia for corneal injuries.

The findings of this study were consistent with those of 3 similar studies in the ophthalmology literature. Each study found that brief outpatient use of dilute topical anesthetic was safe and effective as an analgesic. ${ }^{13-15}$ The clinically significant differences in pain reduction and patient satisfaction in our study demonstrate the efficacy of diluted proparacaine.

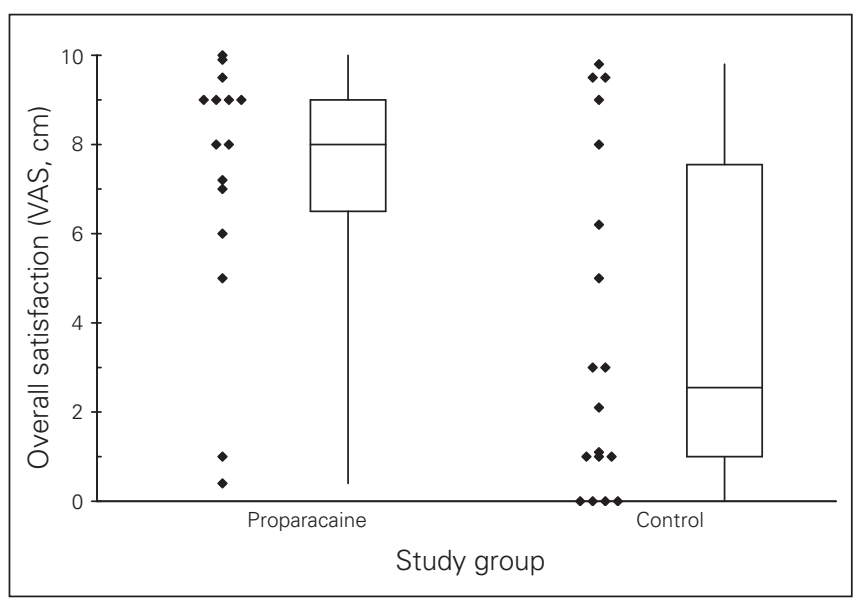

Fig. 2. The diamonds represent the satisfaction scores for each study participant. The upper and lower borders of each rectangle represent the 75th and 25th percentiles of patient satisfaction. The horizontal line within each rectangle represents the median patient satisfaction. VAS = visual analog scale.

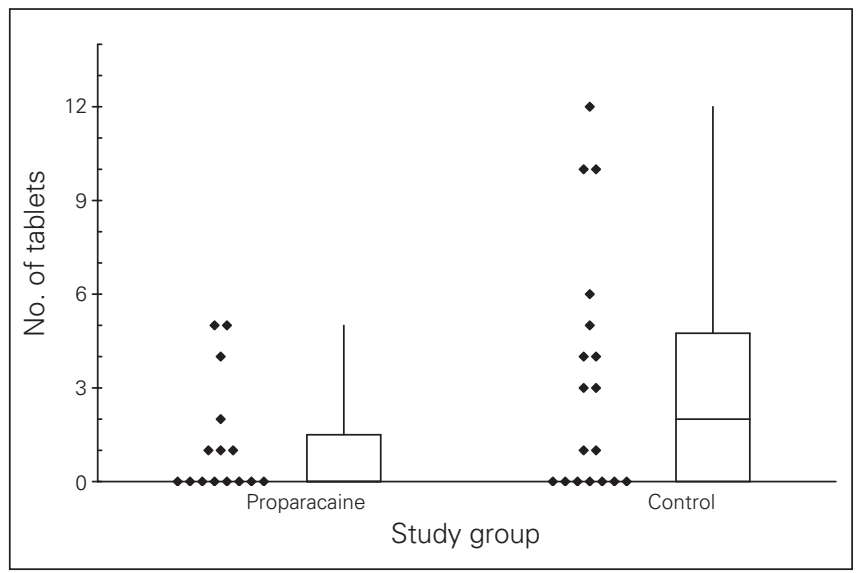

Fig. 3. Rescue doses of oral analgesia. The diamonds represent the mean number of tablets of acetaminophen with codeine used by each patient after each use of the study drug. The upper and lower borders of each rectangle represent the 75th and 25th percentiles of mean number of tablets used per patient. The horizontal line within each rectangle represents the median of the mean number of tablets used per patient. 
Although there was a similar time to pain relief in both groups among the patients who achieved pain relief, a small number of patients in the placebo group continued to use rescue oral acetaminophen with codeine tablets for a longer period.

The literature provides examples of corneal toxicity from repeat application of concentrations of anesthetic intended for 1-time dosing, ${ }^{10-12}$ generally on the order of 10 times greater than the concentration that we used. Such toxicity has also been described with injected $0.75 \%$ bupivacaine, $4 \%$ lidocaine, $0.5 \%$ proparacaine and $0.5 \%$ tetracaine in rabbits. ${ }^{17}$ This same rabbit study supports the safety of dilute injected anesthetic agents. An abundance of evidence exists for the toxicity of topical anesthetic when abused. ${ }^{18-24}$ We did not observe any evidence of harm from dilute-strength topical anesthetic used for a prescribed duration.

Patients in our study were encouraged to use the drops as frequently as needed. Despite the liberal prescription of the study drug, both groups administered most of their drops during the first 24 hours. We speculate that patients in the study drug arm achieved adequate analgesia quickly, and did not require much further analgesic use. Should such patients require analgesia for only 24 to 36 hours, clinicians could prescribe smaller volumes of anesthetic for a shorter duration, which may further improve safety.

The use of prophylactic topical antibiotics in the uncomplicated corneal injury is controversial and not standard practice in our emergency departments. We added topical antibiotics in consultation with ophthalmology colleagues who participated in the study.

Although our study found no evidence of harm from proparacaine, our patients were dispensed a limited volume of dilute anesthetic. Nonetheless, at the end of 5-7 days, all of our patients showed evidence of appropriate injury healing and no patient had continued pain.

\section{Limitations}

This study was performed at a single centre and en rolled a small number of patients. It was not powered for important safety outcomes. We had hoped to enrol consecutive patients but suspect that recruiting physicians missed many eligible patients. No attempt was made to measure the severity or the cause of the corneal injury. We did attempt to verify patient compliance with our protocol by counting remaining tablets, but we did not attempt to measure volume of study drug remaining at follow-up.

\section{CONCLUSION}

Dilute topical anesthetic is an efficacious analgesic in patients with corneal injuries discharged from the emergency department. Treatment with dilute topical anesthetics may be effective and safe when prescribed for 1 to 2 days. Larger studies powered for safety are necessary before widespread adoption of this practice.

Competing interests: None declared.

\section{REFERENCES}

1. Calder L, Balasubramanian S, Stiell I. Corneal abrasion management: national survey shows lack of consensus. CJEM 2004;6:402-7.

2. Sher NA, Frantz JM, Talley A, et al. Topical diclofenac in the treatment of ocular pain after excimer photorefractive keratectomy. Refract Corneal Surg 1993;9:425-36.

3. Marx JA. Red and painful eye. In: Rosen's emergency medicine: concepts and clinical practice. 6th ed. Maryland Heights (MO): Mosby Elsevier; 2006. p. 291.

4. Mitchell JD. Occular emergencies. In: Tintinalli JE, Gabor D, Stapczynski JS, editors. Emergency medicine: a comprehensive study guide. 6th ed. New York (NY): McGraw-Hill Professional; 2004. p. 1455.

5. Havener WH, Mauger TF. Ocular pharmacology. 5th ed. St. Louis (MO): CV Mosby; 1983. p. 75-7.

6. Peyman GA, Rahimy MH, Fernandes ML. Effects of morphine on corneal sensitivity and epithelial wound healing: implication for topical analgesia. Br J Ophthalmol 1994;78: $138-41$

7. Duffin RM, Olson RJ. Tetracaine toxicity. Ann Opbthalmol 1984;16:836-8.

8. Epstein DL, Paton D. Keratitis from the misuse of corneal anesthetics. N Engl J Med 1968;279:396-9.

9. Bartfield JM, Holmes TJ, Raccio-Robak N. A comparison of proparacaine and tetracaine eye anesthetics. Acad Emerg Med 1994;1:364-7.

10. Guzey M, Ahmet S, Dogan B, et al. The effects of bupivicaine and lidocaine on the corneal endothelium when applied into the anterior chamber at the concentrations supplied commercially. Ophthalmologica 2002;216:113-7.

11. Eggeling P, Pleyer U, Hartmann C. Corneal endothelial toxicity of different lidocaine concentrations. I Cataract Refract Surg 2000;26:1403-8.

12. Chang YS, Tseng SH, Chen FK et al. Cytotoxicity of lidocaine 
or bupivacaine on corneal endothelial cells in a rabbit model. Cornea 2006;25:590-6.

13. Verma S, Corbett MC, Patmore A, et al. A comparative study of the duration and efficacy of tetracaine $1 \%$ and bupivacaine $0.75 \%$ in controlling pain following photorefractive keratectomy (PRK). Eur 7 Ophthalmol 1997;7:327-33.

14. Brilakis HS, Thomas MD, Deutsch A. Topical tetracaine with bandage soft contact lens pain control after photorefractive keratectomy. 7 Refract Surg. 2000;16:444-7.

15. Shahinian L, Jain S, Jager RD, et al. Dilute topical proparacaine for pain relief after photorefractive keratectomy. $O p h-$ thalmology 1997;104:1327-31.

16. Price DD, McGrath PA, Rafii A, et al. The validation of visual analogue scales as ratio scale measures for chronic and experimental pain. Pain 1983;17:45-56.

17. Judge AJ, Nafaji K, Lee DA, et al. Corneal endothelial toxicity of topical anesthesia. Ophthalmology 1997;104:1373-9.

18. Rocha G, Brunette I, Le Francois M. Severe toxic keratopathy secondary to topical anesthetic abuse. Can 7 Ophthalmol 1995;30:198-202.

19. Pharmakakis NM, Katsimpris JM, Melachrinou MP, et al Corneal complications following abuse of topical anesthetics. Eur 7 Ophthalmol 2002;12:373-8.

20. Chen HT, Chen KH, Hsu WM. Toxic keratopathy associated with abuse of low dose anesthetic: a case report. Cornea 2004;23:527-9.

21. Ansari H, Garibaldi DC, Jun AS. Anaesthetic abuse keratopathy as a manifestation of ocular Munchausen's syndrome. Clin Experiment Ophthalmol 2006;34:81-3.

22. Varga JH, Rubinfeld RS, Wolf TC, et al. Topical anesthetic abuse ring keratitis: report of four cases. Cornea 1997;16:424-9.

23. Kim JY, Choi YS, Lee JH. Keratitis from corneal anesthetic abuse after photorefractive keratectomy. I Cataract Refract Surg 1997;23:447-9.

24. Sugar A. Topical anesthetic abuse after radial keratectomy. 7 Cataract Refract Surg 1998;24:1535-7.

Correspondence to: Dr. Ian Ball, Queen's University, Kingston General Hospital, 76 Stuart St., Empire 3, Kingston ON K7L 2V7; balli@kgh.kari.net

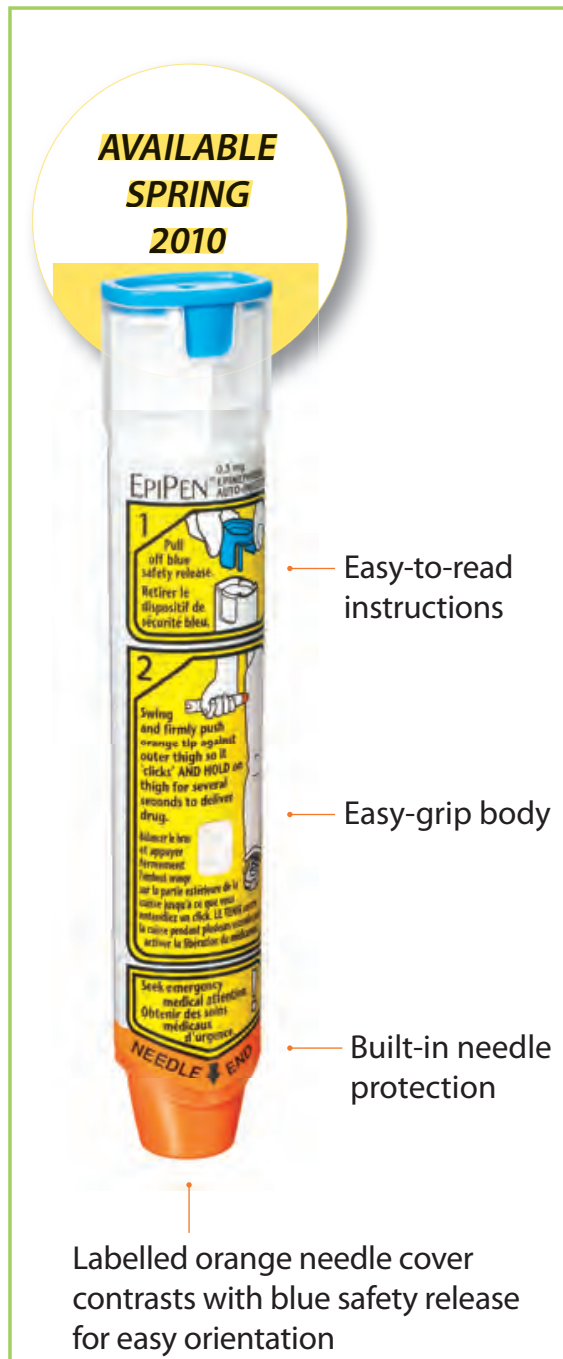

Important Safety Information

EpiPen ${ }^{*}$ and EpiPen ${ }^{*}$ Jr Auto-injectors are indicated for the emergency treatment of anaphylactic reactions in patients who are determined to be at increased risk for anaphylaxis, including individuals with a history of anaphylactic reactions. They are intended for immediate selfadministration for the emergency treatment of severe allergic reactions (Type I), including anaphylaxis associated with foods, stinging and biting insects, medications, latex, other allergens, and for idiopathic and exercise-induced anaphylaxis. Selection of the appropriate dosage strength is determined according to patient body weight.

There are no absolute contraindications to the use of epinephrine in a life-threatening allergic situation. Epinephrine use should be avoided in patients with cardiogenic, traumatic, or hemorrhagic shock; cardiac dilation; and/or cerebral arteriosclerosis. Epinephrine use should be avoided in patients with organic brain damage and in patients with narrow-angle glaucoma. Administer with caution to elderly or hyperthyroid individuals, pregnant women, and individuals with cardiovascular disease or diabetes

Adverse reactions of epinephrine include transient, moderate anxiety; feelings of over stimulation; apprehensiveness; restlessness; tremor; weakness; shakiness; dizziness; sweating; tachycardia; palpitations; pallor; nausea and vomiting; headache; and/or respiratory difficulties. EpiPen and EpiPen ${ }^{\circ}$ Jr Auto-injectors are designed as emergency supportive therapy only. They are not a replacement or substitute for subsequent medical or hospital care, nor are they intended to supplant insect venom hyposensitization 